\title{
Genetic Diversity and Structure of Walnut Populations in Central and Southwestern China Revealed by Microsatellite Markers
}

\author{
Hua Wang and Dong Pei ${ }^{1}$ \\ Key Laboratory of Silviculture, The Institute of Forestry, The Chinese Academy of Forestry, \\ P.O. Box 1958, Beijing 100091, PR China \\ Rui-sheng Gu \\ Institute of Botany, The Chinese Academy of Sciences, Beijing 100093, PR China
}

\author{
Bao-qing Wang \\ College of Forestry, Inner Mongolia Agricultural University, Hohhot 010018, PR China
}

AdDITIONAL INDEX wORDS. Juglans regia, Juglans sigillata, genetic differentiation, genetic relationship, SSR markers

\begin{abstract}
Molecular markers were used to study the genetic diversity, structure, and relationship of Juglans L. with nine populations (five from Juglans regia L. and four from Juglans sigillata Dode) in central and southwestern China. A moderate level of genetic diversity was observed at the population level with the number of effect alleles per locus $\left(A_{\mathrm{E}}\right)$ ranging from 1.75 to 3.35 (average 2.39 ) and the proportion of polymorphic loci $(P)$ equaling $100.0 \%$. The expected heterozygosity $\left(H_{E}\right)$ within populations ranged from 0.389 to 0.687 , and the average was 0.525 . The proportion of genetic variation presented among populations accounted for $18.6 \%$ of the total genetic diversity. The overall gene flow $\left(N_{\mathrm{m}}\right)$ among populations equaled 1.10. The unweighted pair-group method using arithmetic averages (UPGMA) clustering and the Mantel test showed that genetic distances among the nine populations are in a good agreement with their geographic distribution, supporting the viewpoint that J. regia and J. sigillata belong to one species. We suggest that the central area of the southwestern mountain regions of China could be considered as a priority for walnut genetic resource conservation.
\end{abstract}

The genus Juglans is characterized by a monoecious and heterodichogamous habit. It includes about 20 species (Gleeson, 1982; Manning, 1978), distributed over a wide geographical range, including southern Europe, eastern Asia, and the Americas (Krussman, 1986), and displays differentiation in morphology, particularly in nut characteristics. Patterns of population genetic diversity and structures for some species of this genus have been studied by several molecular marker systems, such as isozymes (Arulsekar et al., 1985; Fornari et al., 2001; Solar et al., 1993), restriction fragmentlength polymorphism (RFLP) (Fjellstrom and Parfitt, 1994), randomly amplified polymorphic DNA (RAPD) (Nicese et al., 1998), and intersimple sequence repeat (ISSR) markers (Potter et al., 2002). Simple sequence repeat (SSR) markers exhibit hypervariability and codominance and are highly informative in nature. They exemplify numerous applications in the understanding of the genetic structure of the genus Juglans

\footnotetext{
Received for publication 27 Mar. 2007. Accepted for publication 16 Nov. 2007. We gratefully acknowledge financial support from the National Natural Science Foundation of China (30671436) and the National Key Technology R\&D Program (2006BAD01A17).

Mention of a trademark, proprietary product, or vendor does not constitute a guarantee or warranty of the product by the United States Department of Agriculture and does not imply its approval to the exclusion of other products or vendors that also may be suitable.

The contributions of Yi-chuan Zhu are also acknowledged for his assistance in sample collection. Thanks are also due Drs. Rongling Wu and Arthur Berg (University of Florida, Department of Statistics, Gainesville, Fla.) for their editorial corrections.

${ }^{1}$ Corresponding author. E-mail: peigu@caf.ac.cn.
}

(Dangl et al., 2005; Foroni et al., 2005; Victory et al., 2006; Woeste et al., 2002).

China is an important place for the resources of genus Juglans. There are 12 walnut species that occur there naturally, including the two dominantly cultivated species, Juglans regia and Juglans sigillata (Kuang and Lu, 1979). Juglans sigillata is found only in southwestern China (Qu and Sun, 1990). Despite the significant global economic value of China's nut and wood products, China produces about $27.5 \%$ of the world's total nut production (Food and Agriculture Organization of the United Nations, 2005), and little is known about the genetic diversity and structure of populations like the walnut species in China.

Southwestern China is a special alpine area with various climate and geographical features and a rich plant diversity (Sun, 2002). The Qinling Mountain range, which stretches from the east to west in central China, is particularly rich in plant diversity. It is noteworthy that populations of $J$. sigillata and $J$. regia still grow there, particularly in the canyon regions where human activity, if any, is rare. Moreover, a long-standing debate has arisen about whether $J$. sigillata and J. regia are regarded as completely different species or as just different ecological types (Kuang and Lu, 1979; Wu et al., 2000; Yang and Xi, 1989). Morphological comparisons allowed L.A. Dode to classify $J$. sigillata as a new species in 1906 (as cited in $\mathrm{Xi}$ and Zhang, 1996). Kuang and Lu (1979) put J. regia and J. sigillata into the section Juglans of the Juglans genus. However, on the basis of peroxidase isozyme analysis, Yang and $\mathrm{Xi}$ (1989) suggested that $J$. sigillata and J. regia are two different ecological types of one species. This appears to be supported by hybridization experiments in which the filial 
generation of $J$. regia and $J$. sigillata was observed to be progenitive (Fan and Xi, 2002; Fan et al., 2005; Yang et al., 2007).

The motivation behind this study is to examine the degree of genetic diversity and differentiation of walnuts collected from central and southwestern China and to understand the genetic relatedness of $J$. regia and $J$. sigillata with advanced SSR markers. Our results will provide scientific guidance about effective management, conservation, and improvement of walnut resources.

\section{Materials and Methods}

Plant materials. According to the field investigations of other researchers and the information supplied by local forestry agencies, five representative populations of $J$. regia $(N=154)$ and four representative populations of J. sigillata $(N=132)$ were sampled in the provinces of Yunnan, Sichuan, Shanxi, and Henan in central and southwestern China (Table 1). The populations were all autochthonous, and their sites were not managed. All sampled trees were estimated to be older than 60 years. The plants of J. regia and J. sigillata were distinguished according to their phenotypes (Xi and Zhang, 1996). Six populations (SJC-r, QZ-r, LJ-s, ML-s, YB-s, and MN-s) from southwestern China inhabit disjunctive mountainous areas with a narrow latitudinal and longitudinal range (see Fig. 1). The average distance between any pair of populations was about $80 \mathrm{~km}$. Sampled trees within a population were separated by a distance of more than $50 \mathrm{~m}$. Fresh leaves from each plant were collected and stored at $-80{ }^{\circ} \mathrm{C}$ until DNA extraction for marker analyses.

DNA Extraction. DNA extraction from young leaves followed the method of Doyle and Doyle (1987), with some modification: $1 \mathrm{~g}$ of frozen, ground leaves was added to $10 \mathrm{~mL}$ of pre-heated $\left(50{ }^{\circ} \mathrm{C}\right) 2 \times$ CTAB buffer [ $2 \%$ cetyl trimethyl ammonium bromide, $50 \mathrm{~mm}$ 1,4-dithiothreitol, $0.3 \% \beta$-mercaptoethanol, $1.4 \mathrm{M} \mathrm{NaCl}, 100 \mathrm{~mm}$ Tris, $20 \mathrm{~mm}$ ethylenediaminetetraacetic acid (EDTA), $\mathrm{pH} 8.0$ ] and incubated at $65{ }^{\circ} \mathrm{C}$ for $40 \mathrm{~min}$. The aqueous solution was extracted with $10 \mathrm{~mL}(24: 1)$ of chloroform-isoamyl alcohol and centrifuged at $5^{\circ} \mathrm{C}$ for $10 \mathrm{~min}$ at $10,000 \mathrm{r} / \mathrm{min}$, and the aqueous layer retained; $2 / 3$ volumes of the aqueous layer of $95 \%$ ethanol were added (at $-20{ }^{\circ} \mathrm{C}$ ) to precipitate the nucleic acids. The precipitate was washed with $0.2 \mathrm{M}$ ammonium acetate in $75 \%$ ethanol and air-dried for $5 \mathrm{~min}$. The pellet was then resuspended in $500 \mu \mathrm{L}$ of $65^{\circ} \mathrm{C}$ pre-heated $\mathrm{H}_{2} \mathrm{O}$ and treated with $125 \mu \mathrm{L}\left(10 \mathrm{mg} \cdot \mathrm{mL}^{-1}\right)$ of RNase at $37^{\circ} \mathrm{C}$ for $30 \mathrm{~min}$. The DNA was precipitated, washed, dried, and resuspended in $250 \mu \mathrm{L}$ of $\mathrm{H}_{2} \mathrm{O}$, and quantified in a $1 \%$ agarose gel against Lambda DNA external standards. All samples were then brought to a working concentration of $10 \mathrm{ng} \cdot \mu \mathrm{L}^{-1}$.

PCR AMPLIFICATION AND ELECTROPHORESIS. DNA was amplified using eight microsatellite primers selected from an earlier study in Juglans nigra L. (Woeste et al., 2002) (Table 2). SSR reaction was conducted according to the protocol of Victory et al. (2006) with some modifications. Amplification reaction was performed in a $15-\mu \mathrm{L}$ volume containing $1 \times$ reaction buffer (TaKaRa Biotechnology, Dalian, China), $30 \mathrm{ng}$ of genomic DNA, $0.2 \mathrm{~mm}$ of each dNTP (Promega, Beijing, China), $0.4 \mathrm{~mm}$ of each primer, and 0.9 unit of Taq DNA polymerase (TaKaRa). For DNA amplifications, a GeneAmp PCR System (9700; PerkinElmer, Waltham, MA) was programmed according to the following profile: an initial 3-min incubation at $94{ }^{\circ} \mathrm{C}$; then 30 cycles of $45 \mathrm{~s}$ at $94{ }^{\circ} \mathrm{C}, 30 \mathrm{~s}$ at the annealing temperature (Table 2 ), and $45 \mathrm{~s}$ at $72{ }^{\circ} \mathrm{C}$; and a final incubation at $72{ }^{\circ} \mathrm{C}$ for $5 \mathrm{~min}$. After amplification, $5 \mu \mathrm{L}$ of each sample was loaded and electrophoresed on a $2 \%$ horizontal agarose gel to control for positive amplification and to determine the approximate amount of product. Then, $2 \mu \mathrm{L}$ of each sample was electrophoresed on an $8 \%$ polyacrylamide gel containing $1 \times$ TBE (Tris-borate-EDTA) buffer. After electrophoresis, the gel was silver-stained with the procedure of Panaud et al. (1996). In all cases, PCR reactions were performed at least twice to ensure that absence of bands was not due to a failed reaction.

Allele sCoring AND data analysis. The fragments amplified by microsatellite primers were scored as alleles on the basis of size in a comparison with external standard using a Gel Doc 1000 image analysis system (Bio-Rad, Hercules, CA) and in reference to the expected size in J. nigra (Woeste et al., 2002).

The allele data were entered in the form of single-individual genotypes. The following parameters of genetic variation were assessed for each population: mean number of alleles per locus $(A)$, effective number of alleles $\left(A_{\mathrm{E}}\right)$ (Kimura and Crow, 1964), percentage of polymorphic loci $(99 \%$ criterion) $(P)$, expected heterozygosity $\left(H_{\mathrm{E}}\right)(\mathrm{Nei}, 1978)$, and observed heterozygosity $\left(H_{\mathrm{O}}\right)$. Departures from the Hardy-Weinberg $(\mathrm{H}-\mathrm{W})$ equilibrium were assessed at each locus for every population and per locus across all populations using the $F$ statistics of Wright (1978). The significance of the deviations was evaluated with a $\chi^{2}$ test following the method of Workman and Niswander (1970).

Genetic structures were further analyzed with Wright's analysis of hierarchical $F$ statistics (Wright, 1978). Gene flow $\left(N_{\mathrm{m}}\right)$ was estimated from $N_{\mathrm{m}}=0.25\left(1-F_{\mathrm{ST}}\right) / F_{\mathrm{ST}}$ (Bossart and Prowell, 1998; Whitlock and McCauley, 1999). Nei's (1978) unbiased genetic distances were calculated for all population

Table 1. Walnut populations surveyed and their ecological and geographical parameters.

\begin{tabular}{|c|c|c|c|c|c|c|c|}
\hline Population $^{z}$ & Juglans species & Landform feature & Altitude (m) & Longitude (E) & Latitude (N) & $\begin{array}{c}\text { Annual } \\
\text { rainfall }(\mathrm{mm})\end{array}$ & $\begin{array}{c}\text { Annual avg. } \\
\text { temp. }\left({ }^{\circ} \mathrm{C}\right)\end{array}$ \\
\hline$\overline{\mathrm{FY}-\mathrm{r}}$ & J. regia & Plateau and hilly & 1,414 & $111^{\circ} 30^{\prime}$ & $37^{\circ} 24^{\prime}$ & 438 & 10.2 \\
\hline LC-r & J. regia & Plateau and hilly & 1,130 & $111^{\circ} 30^{\prime}$ & $33^{\circ} 42^{\prime}$ & 672 & 14.7 \\
\hline SJC-r & J. regia & Alpine and canyon & 2,455 & $99^{\circ} 26^{\prime}$ & $28^{\circ} 11^{\prime}$ & 1,250 & 5.1 \\
\hline QZ-r & J. regia & Alpine and canyon & 1,922 & $99^{\circ} 32^{\prime}$ & $27^{\circ} 34^{\prime}$ & 1,050 & 8.2 \\
\hline LJ-s & J. sigillata & Alpine and canyon & 2,566 & $99^{\circ} 45^{\prime}$ & $26^{\circ} 51^{\prime}$ & 980 & 11.0 \\
\hline MN-s & J. sigillata & Alpine and canyon & 1,834 & $102^{\circ} 09^{\prime}$ & $28^{\circ} 36^{\prime}$ & 1,113 & 13.3 \\
\hline
\end{tabular}

" "r" refers to J. regia, and "s" to J. sigillata. 


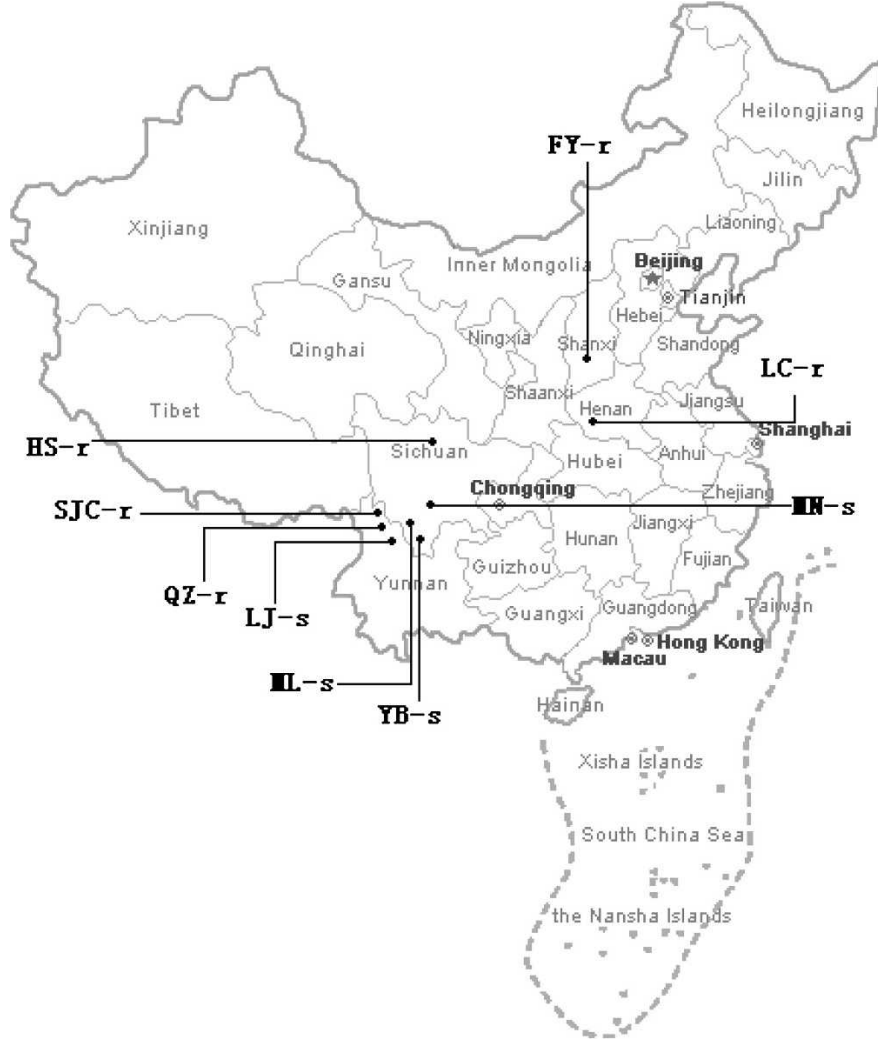

Fig. 1. Names and locations of nine Juglans populations sampled in this study. The letter of "s" at the end of population names refers to J. sigillata, and "r" to J. regia.

pairs and used to construct a phylogenetic tree (UPGMA). All of the above calculations were performed using POPGENE software, version 1.32 (Yeh et al., 1997). The proportion of null alleles was calculated as $\left(H_{\mathrm{E}}-H_{\mathrm{O}}\right) /\left(1+H_{\mathrm{E}}\right)$ (Brookfield, 1996).

The relationship between latitude and the expected heterozygosity was examined via linear regression using Excel
(Office 2003; Microsoft Corp., Redmond, WA). A Mantel test of the association between genetic distance and the geographic distance was performed using GenAlEx6 software (Peakall and Smouse, 2006). Geographic distances were calculated according to the longitude and latitude of every sampled location using CoordTrans software (version 2.3; Franson Technology AB, Johanneshov, Sweden).

\section{Results}

Allelic Variation at microsatellite loci. Based on the SSR analysis, a total of 73 alleles were scored with the sizes ranging from 153 to $306 \mathrm{bp}$ (Table 2). The number of alleles per locus varied from six (WGA-79) to 12 (WGA-42), with an average of 9.13 alleles per locus. Nineteen of the alleles had an overall frequency greater than 0.1 ; the remaining 54 alleles were "rare" with a frequency less than 0.1 , but only 4 of the 54 rare alleles were unique to a single population (private), meaning that $92.6 \%$ of the rare alleles were found in at least two populations.

GeNETIC VARIATION WITHIN POPULATIONS. Genetic diversity parameters based on allelic frequencies are shown in Table 3. In individual population, $A$ varied from 3.25 to 6.00 , with an average of 4.60 , while $A_{\mathrm{E}}$ varied from 1.75 to 3.35 , with an average of 2.39 . $H_{\mathrm{O}}$ ranged from 0.281 to 0.492 , with an average of 0.414 . $H_{\mathrm{E}}$ was 0.525 and varied from 0.389 to 0.687 . For entire populations, $H_{\mathrm{O}}$ and $H_{\mathrm{E}}$ values were 0.411 and 0.632 , respectively, with $A_{\mathrm{E}}=2.91$.

A comparison of the genetic diversity was performed among the nine populations. The highest level of diversity existed in population QZ-r with $H_{\mathrm{E}}$ values of 0.687 , while the lowest values existed in population $\mathrm{HS}-\mathrm{r}$, with $H_{\mathrm{E}}=0.389$. The correlation coefficient between the latitude and the expected heterozygosity in all the populations was significantly negative, $-0.577(P=0.011)$.

Genetic structure. Genetic analyses revealed a high level of differentiation within the populations. The coefficient of hierarchical $F_{\text {ST }}$ (Table 4 ), estimated according to Wright

Table 2. Characterization of the eight SSR markers based on nine walnut populations.

\begin{tabular}{|c|c|c|c|c|c|}
\hline Locus & Repeat type & $\begin{array}{l}\text { Alleles } \\
(\text { no. })^{\mathrm{z}}\end{array}$ & $\begin{array}{c}\text { Ranges of allele } \\
\text { sizes }(b p)^{y}\end{array}$ & $\begin{array}{l}\text { Annealing } \\
\text { temp. }\left({ }^{\circ} \mathrm{C}\right)\end{array}$ & Primer sequence $\left(5^{\prime} \rightarrow 3^{\prime}\right)$ \\
\hline \multirow[t]{2}{*}{ WGA-1 } & \multirow[t]{2}{*}{$(\mathrm{AG})_{6} \mathrm{C}(\mathrm{AG})_{3}$} & \multirow[t]{2}{*}{10} & $189-221$ & \multirow[t]{2}{*}{60} & F : ATTGGAAGGGAAGGGAAATG \\
\hline & & & $189-207$ & & R : CGCGCACATACGTAAATCAC \\
\hline WGA-42 & $(\mathrm{GA})_{14}$ & 12 & $210-260$ & 55 & R : AACTTTGCACCACATCCACA \\
\hline WGA-70 & $(\mathrm{GA})_{14}$ & 10 & $161-177$ & 55 & F : TGTAATTGGGGAATGTTGCA \\
\hline WGA-71 & $(\mathrm{GA})_{6}(\mathrm{G})_{12}$ & 8 & $212-228$ & 57 & R : GGACCCAGCTCCTCTTCTCT \\
\hline \multirow[t]{2}{*}{ WGA-72 } & \multirow[t]{2}{*}{$(\mathrm{CT})_{14}$} & \multirow[t]{2}{*}{8} & $153-173$ & \multirow[t]{2}{*}{58} & F : AAACCACCTAAAACCCTGCA \\
\hline & & & $153-173$ & & R : ACCCATCCATGATCTTCCAA \\
\hline \multirow[t]{2}{*}{ WGA-76 } & \multirow[t]{2}{*}{$(\mathrm{GA})_{12}$} & \multirow[t]{2}{*}{10} & $242-306$ & \multirow[t]{2}{*}{55} & F : AGGGCACTCCCTTATGAGGT \\
\hline & & & $246-302$ & & R : CAGTCTCATTCCCTTTTTCC \\
\hline WGA-79 & $(\mathrm{GA})_{12}$ & 6 & $204-220$ & 55 & F : CACTGTGGCACTGCTCATCT \\
\hline
\end{tabular}

${ }^{\mathrm{z}}$ Number of alleles observed for each marker.

${ }^{\mathrm{y}}$ Top ranges are for J. regia; bottom ranges are for J. sigillata. 
Table 3. Genetic variation within nine Juglans populations based on eight SSR loci.

\begin{tabular}{lccccc}
\hline Population & $N^{\mathrm{z}}$ & $A^{\mathrm{y}}$ & $A_{\mathrm{E}}{ }^{\mathrm{x}}$ & $H_{\mathrm{O}}{ }^{\mathrm{w}}$ & $H_{\mathrm{E}}{ }^{\mathrm{w}}$ \\
\hline FY-r & 33 & 3.63 & 1.82 & 0.343 & 0.401 \\
LC-r & 31 & 3.25 & 2.08 & 0.348 & 0.431 \\
HS-r & 30 & 3.63 & 1.75 & 0.281 & 0.389 \\
SJC-r & 33 & 5.25 & 2.73 & 0.476 & 0.603 \\
QZ-r & 27 & 6.00 & 3.35 & 0.492 & 0.687 \\
LJ-s & 33 & 5.13 & 2.82 & 0.490 & 0.639 \\
ML-s & 33 & 4.25 & 2.22 & 0.430 & 0.506 \\
YB-s & 33 & 5.25 & 2.43 & 0.423 & 0.548 \\
MN-s & 33 & 5.00 & 2.33 & 0.440 & 0.519 \\
Mean & 32 & 4.60 & 2.39 & 0.414 & 0.525 \\
Total & 286 & 9.13 & 2.91 & 0.411 & 0.632 \\
\hline
\end{tabular}

${ }^{\mathrm{z}}$ Sample size.

${ }^{\mathrm{y}}$ Mean number of alleles.

${ }^{x}$ Effective number of alleles per locus.

${ }^{\mathrm{w}}$ Observed heterozygosity.

${ }^{\vee}$ Expected heterozygosity.

(1978), ranged from 0.140 for locus WGA-70 to 0.248 for locus WGA-79, with the average value equaling 0.186 . This indicates that, on average, $18.6 \%$ of the total genetic diversity present is present within a given population. All loci possessed a close $F_{\mathrm{ST}}$ value except locus WGA-79. The overall gene flow $\left(N_{\mathrm{m}}\right)$ among populations was 1.097 , which gave an estimate of the average number of migrants between all studied populations per generation. The observed value indicated that gene exchange between populations is low.

Genotypic STRUCTURE. In individual populations, tests for the departure from $\mathrm{H}-\mathrm{W}$ equilibrium showed significant deviations for at least one locus in every population. The $\chi^{2}$ test $(P<0.05)$ indicated that significant departures from the $\mathrm{H}-\mathrm{W}$ equilibrium appeared in many cases $(\approx 60 \%)$. The deviations were primarily attributed to a deficit of heterozygotes.

$F_{\text {IT }}$ is the overall inbreeding coefficient of an individual relative to the whole set of populations, while $F_{\text {IS }}$ is the inbreeding coefficient of an individual relative to its own population. The mean $F_{\text {IT }}$ value of 0.348 indicates that, overall, nine populations have a deficiency of heterozygotes. Within populations, all loci but one $\left(\mathrm{WGA}-42, F_{\text {IS }}=-0.106\right)$ contained a deficiency of heterozygotes ( $F_{\text {IS }}$ ranging from 0.047 to 0.417 ), with an average $F_{\text {Is }}$ value of 0.199 , which is significantly different from zero (Table 4 ). This suggested that there was a regular tendency toward heterozygote deficiency and indicated the presence of inbreeding within the populations. In addition, the proportion of null alleles was estimated, and they were found to occur at a moderate frequency: for eight loci, the estimated values varied from 0.04 to 0.22 (Table 4 ) and the mean value equaled 0.13 .

Genetic Relationships. Genetic distances were calculated for each pair of populations to estimate the extent of their divergence (Table 5). In the nine populations, the average genetic distance among populations equaled 0.311 . The lowest genetic distance (0.049) was found between populations YB-s and $\mathrm{MN}-\mathrm{s}$, and the greatest genetic distance (0.845) was found between populations LC-r and MN-s. In addition, The average genetic distances between $J$. regia populations is 0.222 , that between $J$. sigillata populations is 0.122 , and that for $J$. regia-to-J. sigillata is 0.423 .

The UPGMA cluster analyses based on Nei's unbiased genetic distances was performed to further show the genetic relationships among the populations (Fig. 2). The dendrogram separates the nine populations into two main groups. The first group consists of populations SJC-r, QZ-r, LJ-s, MN-s, YB-s, and ML-s. In this group, population QZ-r differs considerably from the others. The second group consists of populations FY-r, LC-r, and HS-r. In this group, populations FY-r and LC-r cluster together while population HS-r was more distant. A Mantel test with 1000 random permutations revealed a significant correlation between pairwise genetic distance and geographic distances among the nine sampled populations $\left(R^{2}=\right.$ $0.354, P<0.005)$.

\section{Discussion}

We observed a moderate genetic diversity in nine walnut populations in central and southwestern China based on 73 loci alleles. The expected heterozygosity $\left(H_{\mathrm{E}}\right)$ of the populations ranged from 0.389 to 0.687 , and their mean $H_{\mathrm{E}}$ was 0.525 . In comparison, the average $H_{\mathrm{E}}$ of those nine populations was lower than that observed in other Juglans species, e.g., in J. nigra (mean $H_{\mathrm{E}}=0.807$ ) (Victory et al., 2006) and Juglans mandshurica Max. (mean $H_{\mathrm{E}}=0.806$ ) (W.N. Bai, unpublished data), and in some temperate forest tree species (Derory et al.,

Table 4. Genetic differentiation and gene flow among nine Juglans populations.

\begin{tabular}{|c|c|c|c|c|c|c|c|}
\hline Loci & $F_{\mathrm{IS}}^{\mathrm{z}}$ & $F_{\mathrm{IT}^{\mathrm{y}}}^{\mathrm{y}}$ & $F_{\mathrm{ST}}^{\mathrm{x}}$ & $N_{\mathrm{m}}{ }^{\mathrm{w}}$ & $H_{\mathrm{O}}$ & $H_{\mathrm{E}}$ & $\begin{array}{c}\text { Proportion of } \\
\text { null alleles }\end{array}$ \\
\hline$\overline{\text { WGA-01 }}$ & 0.406 & 0.522 & 0.196 & 1.029 & 0.350 & 0.731 & 0.22 \\
\hline WGA-42 & -0.106 & 0.103 & 0.189 & 1.071 & 0.578 & 0.648 & 0.04 \\
\hline WGA-71 & 0.089 & 0.278 & 0.208 & 0.952 & 0.382 & 0.540 & 0.10 \\
\hline WGA-72 & 0.198 & 0.315 & 0.146 & 1.469 & 0.345 & 0.498 & 0.10 \\
\hline WGA-76 & 0.327 & 0.422 & 0.141 & 1.525 & 0.278 & 0.480 & 0.14 \\
\hline WGA-89 & 0.152 & 0.322 & 0.201 & 0.993 & 0.491 & 0.729 & 0.14 \\
\hline Mean & 0.199 & 0.348 & 0.186 & 1.097 & 0.411 & 0.631 & 0.13 \\
\hline
\end{tabular}

${ }^{\mathrm{z}}$ Inbreeding coefficient at the population level.

y Inbreeding coefficient at the total sample level.

${ }^{x}$ Proportion of differentiation among populations.

${ }^{\mathrm{w}}$ Gene flow estimated from $N_{\mathrm{m}}=0.25\left(1-F_{\mathrm{ST}}\right) / F_{\mathrm{ST}}$.

vProportion of null alleles $=\left(H_{\mathrm{E}}-H_{\mathrm{O}}\right) /\left(1+H_{\mathrm{E}}\right)$. 
Table 5. Nei's unbiased measures of genetic identities (above the diagonal) and genetic distances (below the diagonal) among nine Juglans populations (Nei, 1978).

\begin{tabular}{|c|c|c|c|c|c|c|c|c|c|}
\hline Population & FY-r & LC-r & HS-r & SJC-r & QZ-r & LJ-S & ML-S & YB-s & $\overline{\mathrm{MN}-\mathrm{s}}$ \\
\hline FY-r & $* * * *$ & 0.937 & 0.890 & 0.819 & 0.720 & 0.624 & 0.728 & 0.515 & 0.495 \\
\hline HS-r & 0.116 & 0.234 & $* * * *$ & 0.845 & 0.780 & 0.664 & 0.738 & 0.597 & 0.597 \\
\hline QZ-r & 0.328 & 0.482 & 0.248 & 0.103 & $* * * *$ & 0.788 & 0.807 & 0.759 & 0.734 \\
\hline LJ-s & 0.472 & 0.544 & 0.409 & 0.179 & 0.238 & $* * * *$ & 0.894 & 0.856 & 0.860 \\
\hline ML-S & 0.318 & 0.367 & 0.304 & 0.078 & 0.215 & 0.112 & $* * * *$ & 0.896 & 0.859 \\
\hline MN-s & 0.704 & 0.845 & 0.515 & 0.296 & 0.310 & 0.151 & 0.152 & 0.049 & $* * * *$ \\
\hline
\end{tabular}

2002; Heuertz et al., 2004; Jones et al., 2002; Muir et al., 2004). As an economically important species, walnut plants were inevitably disturbed by human activities, such as deforestation and selection (Lee and Lee, 1997), particularly over the past 100 years. Consequently, many walnut genetic resources have been fragmented or lost entirely. Those that remain are located only along canyons and besides streams and rivers. The Juglans species are monoecious woody plants with separate male and female inflorescences and a wind-pollinated out-crossing mating system (Gleeson, 1982); its pollen has at most only $300 \mathrm{~m}$ of transmitting distance by wind (Han et al., 1996). Therefore, fragmentation can induce a certain level of genetic drift. Moreover, the $J$. regia and J. sigillata species have higher percentages of self-pollination and parthenogenesis (Fan and Xi, 2002; Wang, D.L., et al., 1999; Wang, G.A., et al., 2003). Self-pollination is generally considered a more important factor of a population's genetic diversity level (Charlesworth and Charlesworth, 1987). Therefore, human disturbance, mating system, and self-pollination could be the major causes for the lower level of genetic diversity in the nine walnut populations compared with other Juglans species and temperate forest tree species.

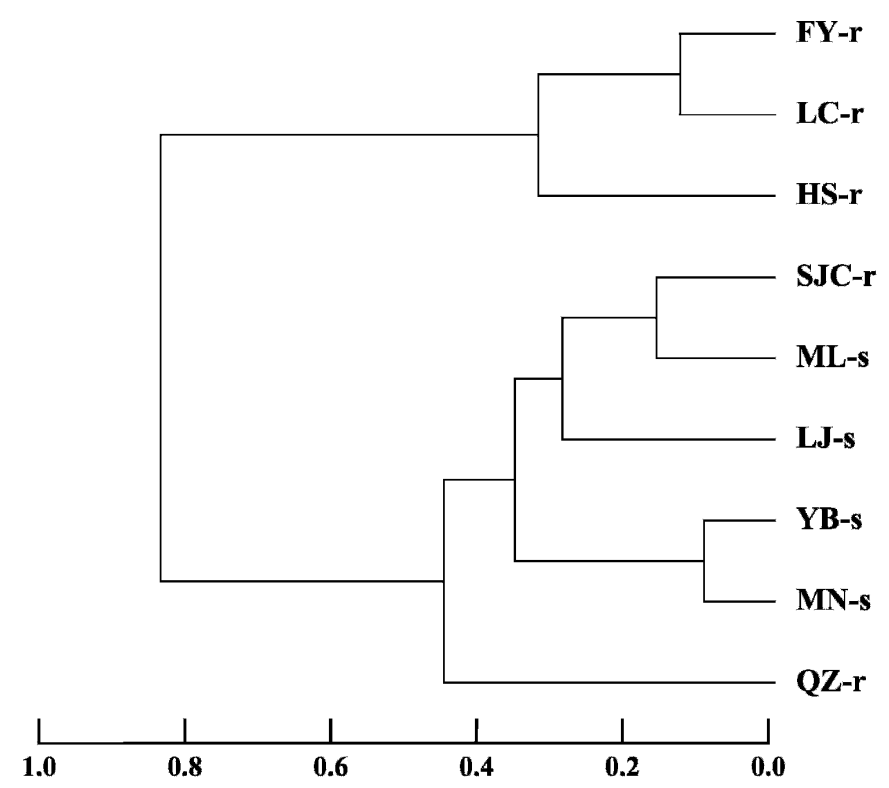

Fig. 2. UPGMA dendrogram of nine Juglans populations in central and southwestern China based on Nei's unbiased genetic distances. The letter of "s" at the end of population names refers to J. sigillata, and "r" to J. regia.
The genetic analyses of the nine populations showed a high level of differentiation among populations. The coefficient of hierarchical $F_{\mathrm{ST}}$ among populations ranged from 0.140 to 0.248 . Its mean $F_{\mathrm{ST}}$ was 0.186 , indicating that $18.6 \%$ of the total genetic diversity existed among populations and $81.4 \%$ within populations. This result was consistent with the variation models reported in anemophilous pines (Yeh and Layton, 1997). The high level of interpopulation differentiation might result from the differentiation of habitats, for instance, with respect to climate, temperature, annual rainfall, or landform features. Southwestern China is located in the center area of Himalayan-Hengduan Mountains and is characterized by rolling hills, high peaks, and criss-crossing valleys and canyons. It contains various geographical features and microenvironments. Heterogeneous environments promote maintenance of high genetic diversity due to developmental homeostasis (Lerner, 1954). Various climate and ecological conditions in these areas have led to a high species diversity and genetic diversity (Peng et al., 2005). The Himalayan-Hengduan Mountains and surrounding areas are considered to be a new concentration area of temperate and alpine plants due to their geographic and environmental characteristics (Ming et al., 2006; Sun, 2002). Suitable habitats and little disturbance by human activities might be the main reasons for the high diversity within these walnut populations.

The genetic diversity of the nine populations presented a geographic gradient. Six populations distributed in the southwest mountains of China (LJ-s, ML-s, YB-s, MN-s, SJC-r, and QZ-r) had a higher level of genetic diversity within populations than those in the northward areas. A negative correlation between latitude and $H_{\mathrm{E}}$ in the nine populations was detected. This result seems to be consistent with the viewpoint proposed by Lu and Zhang (1990) that walnuts were indigenous to the tropical mountains in southwestern China, but-because of the seasonal drought that persists there-they evolved their sustainability from a humid environment in torrid zones to a drier environment. Populations of SJC-r, QZ-r, and LJ-s, distributed in the central area of the southwest mountains of China (in northwestern Yunnan Province), had a higher genetic diversity than other populations, and those three populations captured more than $95 \%$ of the genetic variation presented in all populations under investigation. Therefore, we could consider this region as an important hotspot of walnut diversity.

L.A. Dode considered J. sigillata as a different species from $J$. regia mainly based on leaf morphological difference. For instance, J. regia grows elliptic to ovate leaflets, has 5-9 leaflets in a compound leaf, and has less than 15 pairs of lateral veins in a leaflet, whereas $J$. sigillata grows elliptic to 
ovate-lanceolate leaflets, has 9-11 leaflets in a compound leaf, and has 15-33 pairs of lateral veins in a leaflet (Kuang and Lu, 1979). However, plant morphology, particularly leaf morphology, is influenced strongly by the environment. The genetic diversity of these two species based on isozymes markers showed no significant difference between them (Yang and $\mathrm{Xi}$, 1989). Kuang and Lu (1979) classified J. regia and J. sigillata into the section Juglans under the Juglans genus on the basis of plant morphologic and geographic characteristics. A crossing result of $J$. regia $\times J$. sigillata showed that their filial generation was progenitive (Fan and Xi, 2002; Fan et al., 2005). Some offspring of $J$. regia generated by cross-fertilization with $J$. sigillata or self-fertilization in the scope of $J$. sigillata distribution exhibited morphological characteristics of J. sigillata (Fan et al., 2005). In this research, UPGMA clustering showed that the nine populations considered were congregated according to their geographic distribution rather than the definition of traditional taxonomy, suggesting that the genetic differentiation of $J$. regia and $J$. sigillata was small. A Mantel test with 1000 random permutations revealed a significant correlation between pairwise genetic distance and geographic distances among the nine sampled populations $\left(R^{2}=0.354, P<0.005\right)$. This result supports the viewpoint that $J$. regia and $J$. sigillata are different ecological types of the same species. Their differentiation might result from geographic migration and reproductive isolation.

\section{Literature Cited}

Arulsekar, S., D.E. Parfitt, and G.H. McGranahan. 1985. Isozyme gene markers in Juglans species. J. Hered. 76:103-106.

Bossart, J.L. and D.P. Prowell. 1998. Genetic estimates of population structure and gene flow: Limitations, lessons and new directions. Trends Ecol. Evol. 13:202-206.

Brookfield, J.F. 1996. A simple new method for estimating null allele frequency for heterozygote deficiency. Mol. Ecol. 5:453-455.

Charlesworth, B. and D. Charlesworth. 1987. Inbreeding depression and its evolutionary consequences. Annu. Rev. Ecol. System. 18:237-268.

Dangl, G.S., K. Woeste, M.K. Aradhya, A. Koehmstedt, and C. Simon. 2005. Characterization of 14 microsatellite markers for genetic analysis and cultivar identification of walnut. J. Amer. Soc. Hort. Sci. 130:348-354.

Derory, J., S. Mariette, S.C. Gonzalez-Martinez, D. Chagne, D. Madura, S. Gerber, J. Brach, F. Persyn, M.M. Ribeiro, and C. Plomion. 2002. What can nuclear microsatellites tell us about maritime pine genetic resources conservation and provenance certification strategies? Ann. Sci. 59:699-708.

Doyle, J.J. and J.L. Doyle. 1987. A rapid DNA isolation procedure for small quantities of fresh leaf tissue. Phytochem. Bul. 19:11-15.

Fan, Z.Y. and X.L. Xi. 2002. Five new early bearing fruit Juglans varieties developed by crossing Juglans sigillata Dode and Juglans regia Linn. (in Chinese). Hunan For. Sci. Technol. 29:66-68.

Fan, Z.Y., W.L. Fang, and R.Q. Dong. 2005. Comparison and selection of pollinated Biyangpao walnut varieties (in Chinese). South China Fruits 34:58-59.

Fjellstrom, R.G. and D.E. Parfitt. 1994. Walnut (Juglans spp.) genetic diversity determined by restriction fragment length polymorphisms. Genome 37:690-700.

Food and Agriculture Organization of the United Nations. 2005. Agricultural production, crops primary. FAO, Geneva. 13 Nov. 2006. <http://apps.fao.org/faostat/>.

Fornari, B., M.E. Malvolti, and D. Taurchini. 2001. Isozyme and organellar DNA analysis of genetic diversity in natural/naturalised European and Asiatic walnut (Juglans regia L.) populations. Acta Hort. 544:167-178.
Foroni, I., R. Rao, K. Woeste, and M. Gallitelli. 2005. Characterisation of Juglans regia L. with SSR markers and evaluation of genetic relationships among cultivars and the 'Sorrento' landrace. J. Hort. Sci. Biotechnol. 80:49-53.

Gleeson, S.K. 1982. Heterodichogamy in walnuts: Inheritance and stable ratios. Evolution 36:892-902.

Han, T.Z., P.Z. Luo, H.P. Jia, and G.L. Zhang. 1996. The experiment of walnut pollination by manpower assistance (in Chinese). J. Fruit Sci. 13:31-32.

Heuertz, M., J.F. Hausman, O.J. Hardy, G.G. Vendramin, N. FrascariaLacoste, and X. Vekemans. 2004. Nuclear microsatellites reveal contrasting patterns of genetic structure between western and southeastern European populations of the common ash (Fraxinus excelsior L.). Evolution 58:976-988.

Jones, R.C.D., A.B. Steane, M. Potts, and R.E. Vaillancourt. 2002. Microsatellite and morphological analysis of Eucalyptus globulus populations. Can. J. For. Res. 32:59-66.

Kimura, M. and J. Crow. 1964. The number of alleles that can be maintained in a finite population. Genetics 49:725-738.

Krussman, G. 1986. Manual of cultivated broad-leaved trees and shrubs, Vol. II. Timber Press, Portland, Ore.

Kuang, K.Z. and A.M. Lu. 1979. Flora of China. Vol. 21 (in Chinese). Science Press, Beijing, China.

Lee, S.W. and M.H. Lee. 1997. Genetic variation of Juglans sinensis in Korea. Silvae Genet. 46:102-107.

Lerner, I.M. 1954. Genetic homeostasis. Oliver and Boyd, Edinburgh. Lu, A.M. and Z.Y. Zhang. 1990. The differentiation, evolution and systematic relationship of Juglandales (in Chinese). Acta Phytotaxon. Sinica 28:96-102.

Manning, W.E. 1978. The classification within the Juglandaceae. Ann. Missouri Bot. Garden 65:1058-1087.

Ming, Q.Z., Z.T. Shi, and H.C. Zhang. 2006. The evolution of the landform and environment in the region of the three parallel rivers (in Chinese). Trop. Geogr. 26:119-122.

Muir, G., A.J. Lowe, C.C. Fleming, and C. Vogl. 2004. High nuclear genetic diversity, high levels of outcrossing and low differentiation among remnant populations of Quercus petraea at the margin of its range in Ireland. Ann. Bot. (Lond.) 93:691-697.

Nei, M. 1978. Estimation of average heterozygosity and genetic distance from a small number of individuals. Genetics 89:583-590.

Nicese, E.P., J.I. Hormaza, and G.H. McGranahan. 1998. Molecular characterization and genetic relatedness among walnut (Juglans regia L.) genotypes based on RAPD markers. Euphytica 101:199206.

Panaud, O., X. Chen, and S.D. McCouch. 1996. Development of microsatellite markers and characterization of sample sequence length polymorphism (SSLP) in rice (Oryzastiva L.). Mol. Gen. Genet. 252:597-607.

Peakall, R. and P.E. Smouse. 2006. GenAlEx6: Genetic analysis in Excel. Population genetic software for teaching and research. Mol. Ecol. Notes 6:288-295.

Peng, Y., Z. Lu, and K. Chen. 2005. Population genetic survey of Populus cathayana originating from southeastern Qinghai-Tibetan plateau of China based on SSR markers. Silvae Genet. 54:116-122.

Potter, D., F. Gao, G. Aiello, C. Leslie, and G. McGranahan. 2002. Inter-simple sequence repeat markers for fingerprinting and determining genetic relationships of walnut (Juglans regia) cultivars. J. Amer. Soc. Hort. Sci. 127:75-81.

Qu, Z.Z. and Y.W. Sun. 1990. Varieties of China fruit tree (in Chinese). Agricultural Press, Beijing, China.

Sun, H. 2002. Evolution of Arctic-tertiary flora in HimalayanHengduan Mountains (in Chinese). Acta Bot. Yunnan. 24(6):671688.

Solar, A., J. Smole, and F. Stampar. 1993. Identification of walnut cultivars by pollen isozymes. Acta Hort. 311:95-99.

Victory, E.R., J.C. Glaubitz, O.E. Rhodes, Jr and K.E. Woeste. 2006. Genetic homogeneity in Juglans nigra (Juglandaceae) at nuclear microsatellites. Amer. J. Bot. 93:118-126. 
Wang, D.L., D.L. Liu, and Q. Zhang. 1999. Study on the pollination characters of Yunnan Ma walnut (Juglans sigillata Dode) (in Chinese). Hunan For. Sci. Technol. 26:19-24.

Wang, G.A., W.G. Cui, and B. Tu. 2003. The application of parthenogenesis in genetic purification of Juglans regia varieties (in Chinese). Xinjiang Agr. Sci. 40:90-93.

Whitlock, M.C. and D.E. McCauley. 1999. Indirect measures of gene flow and migration: $F_{\mathrm{ST}}$ not equal to $1 /\left(4 N_{\mathrm{m}}+1\right)$. Heredity $82: 117-125$.

Woeste, K., R. Burns, O.E. Rhodes, Jr., and C. Michler. 2002. Thirty polymorphic nuclear microsatellite loci from black walnut. J. Hered. 93:58-60.

Workman, P.L. and J.D. Niswander. 1970. Population studies on southwestern Indian tribes. II. Local genetic differentiation in the Papago. Am. J. Hum. Genet. 22:24-49.

Wright, S. 1978. Evolution and genetics of populations, Vol. 4: Variability within and among populations. University of Chicago Press, Chicago.
Wu, Y.M., D. Pei, and S.K. Xi. 2000. A study on relationship among species in Juglans L. using RAPD markers (in Chinese). Acta Hort. Sinica 27:17-22.

Xi, R.T. and Y.P. Zhang. 1996. Fruit trees of China. Walnut (in Chinese). Chinese Forestry Press, Beijing, China.

Yang, Y., B.C. Chen, B.Q. Li, X.T. Xin, and Y.D. Zhang. 2007. Breeding of new walnut varieties 'Yangza 1', 'Yangza 2' and 'Yangza 3' (in Chinese). Deciduous Fruits 39:13-15.

Yang, Z.X. and S.K. Xi. 1989. A study on isozymes of peroxidase of 10 species in Juglans L. (in Chinese). Acta Phytotaxon. Sinica 27: 53-57.

Yeh, F.C. and C. Layton. 1997. The organization of genetic variability in central and marginal populations of lodgepole pine Pinus contorta ssp. latifolia. Can. J. Genet. Cytol. 21:487-503.

Yeh, F.C., R.C. Yang, and T. Boyle. 1997. POPGENE, version 1.32 ed. Microsoft Windows-based freeware for population genetic analysis. University of Alberta, Edmonton, Canada. 